\title{
RANCANG BANGUN SISTEM PENDUKUNG KEPUTUSAN PEMILIHAN PERUMAHAN DENGAN METODE AHP DAN GIS
}

\author{
Al Fath Riza Kholdani ${ }^{1}$, Desy Ika Puspitasari², Tri Wahyu Qur'ana ${ }^{3}$ \\ ${ }^{1}$ Fakultas Teknologi Informasi, Universitas Islam Kalimantan Muhammad Arsyad Al Banjari \\ 1 email : kholdanialfath@gmail.com \\ ${ }^{2}$ Fakultas Teknologi Informasi, Universitas Islam Kalimantan Muhammad Arsyad Al Banjari ${ }^{2}$ email : \\ smile4desyka@gmail.com \\ ${ }^{3}$ Fakultas Teknologi Informasi, Universitas Islam Kalimantan Muhammad Arsyad Al Banjari \\ 3 email : twqurana@gmail.com
}

\begin{abstract}
Abstrak
Masyarakat yang belum memiliki rumah tinggal saat ini masih mengalami kesulitan dalam mencari perumahan yang ideal dan sesuai kriteria yang diinginkannya. Misalkan pencarian perumahan berdasarkan harga, ukuran tanah, ukuran tipe rumah, lokasi perumahan, fasilitas yang tersedia dan sebagainya. Belum lagi adanya masalah beberapa developer nakal atau perumahan bodong yang meresahkan masyarakat di Kalimantan Selatan.SPK(Sistem Pendukung Keputusan) merupakan sistem informasiinteraktif yang menyediakan informasi, pemodelan, dan pemanipulasian data untuk membantu pengambilan keputusan.AHP (Analytical Hierarchy Process) merupakan metode yang digunakan untuk memecahkan masalah yang kompleks dan tidak terstruktur ke dalam kelompokkelompok dengan mengatur kelompok tersebut ke dalam suatu hierarki, kemudian memasukkan nilai numerik sebagai pengganti persepsi manusia dalam melakukan perbandingan relatif. GIS(Geographic Information System) merupakan suatu sistem informasi yang berbasis komputer, dirancang untuk bekerja dengan menggunakan data yang memiliki informasi spasial (bereferensi keruangan). Penelitian ini bertujuan membantu dan memudahkan bagi calon pembeli perumahan dalam mencari, memilih dan menentukan perumahan berdasarkan keinginan dan kemampuan calon pembeli tentang bentuk fisik perumahan, harga, fasilitas dan lokasi yang diinginkan.
\end{abstract}

Kata kunci : AHP, GIS, Lokasi perumahan, Pencarian, SPK

\section{PENDAHULUAN}

Perumahan adalah kelompok rumah yang berfungsi sebagai lingkungan tempat tinggal atau lingkungan hunian yang dilengkapi dengan prasarana dan sarana lingkungan yang baik (Ramlan, Purwanto, Eosina, \& Susetyo, 2018). Permukiman adalah bagian dari lingkungan hidup di luar kawasan lindung, baik yang berupa kawasan perkotaan maupun perdesaan yang berfungsi sebagai lingkungan tempat tinggal atau lingkungan hunian dan tempat kegiatan yang mendukung perikehidupan dan penghidupan (Farizki \& Anurogo, 2017).

Dalam Pembukaan UUD 1945 dan Pasal $28 \mathrm{H}$ ayat 1 UUD 1945 juga menegaskan bahwa setiap warga negara mempunyai hak untuk menempati dan atau menikmati dan atau memiliki rumah yang layak dalam lingkungan yang sehat, aman, serasi, dan teratur.

Saat ini, masyarakat yang belum memiliki rumah tinggal mengalami kesulitan dalam mencari perumahan yang ideal dan sesuai kriteria yang diinginkannya. Misalkan masalah harga dan biaya-biaya lainnya, ukuran tanah, peningkatan mutu, lokasi perumahan dan sebagainya. Belum lagi masalah adanya beberapa developer nakal atau perumahan bodong yang meresahkan masyarakat di Kalimantan Selatan. Kurangnya informasi dan sosialisasi dari pemerintah daerah tentang perumahan dan permukiman yang legal dan ideal membuat masyarakat tergiur akan perumahan fiktif yang menjanjikan janji-janji palsu. Pada sisi 
lain, Pemerintah Pusat melalui Kementerian Pekerjaan Umum dan Perumahan Rakyat (PUPR) menargetkan realisasi Subsidi Bantuan Uang Muka (SBUM) tahun 2017 bisa digunakan untuk 550 ribu unit rumah MBR. Adapun program pembiayaan perumahan di tahun 2017 meliputi Program KPR Sejahtera FLPP (Fasilitas Likuiditas Pembiayaan Perumahan), Subsidi Selisih Bunga, Bantuan Uang Muka.

Lokasi titik koordinat perumahan dan permukiman belum terkelola dengan baik, padahal dari sisi pemerintah di Instansi Badan Pertanahan Nasional menerbitkan sertifikat tanah wajib menyertakan titik koordinat. Faktor daya tarik dalam pemasaran perumahan ialah aksesibilitas yang baik, biasanya yang menjadi bahan pertimbangan konsumenyakni kemudahan dalam mencapaipusat kegiatan seperti sekolah, kantor (tempat bekerja) atau pusat-pusat perekonomian dalam penentuan lokasi perumahan yang akan mereka jadikan tempat tinggal (Panggabean, 2015).AHP (Analytical Hierarchy Process) dalam penelitian ini merupakan metode yang digunakan dengan sistem interaktif berbasis komputer untuk memecahkan masalah yang kompleks dan tidak terstruktur (Kholdani, Muflih, \& Arminarahmah, 2017). GIS (Geographic Information System) merupakan sistem komputer yang dapat digunakan untuk mengolah data, menganalisis dan menampilkan data yang berhubungan dengan posisi permukaan bumi (keruangan) (Puspitasari \& Kurniawan, 2019). Sistem pendukung keputusan diperlukan pada penelitian ini dalam mendukung pemilihan perumahan yang baik sesuai keinginan dan kebutuhan calon pembeli untuk menentukan keputusan yang diambil agar lebih tepat sasaran (Puspitasari \& Kholdani, 2017).

Penelitian terkait yang menjadi acuan ialah yang dilakukan oleh (Riyanto, Bintro, \& Pambudi, 2018) sistem pendukung keputusan yang dapat digunakan para pengembang perumahan untuk penentuan lokasi strategis pembangunan perumahan menggunakan metode AHP, hasil analisis yang didapat dari kriteria tertinggi. Penelitian selanjutnya yang dilakukan oleh (Zuo, Jiangfeng, Yanzhong, \& Biao, 2009) yang membuat aplikasi dengan mengintegrasikan GIS dan sistem pendukung keputusan spasial yang bermanfaat untuk administrator dalam memilih lokasi untuk bangunan perumahan baru yang terjangkau di Tingkok, Cina. Sistem pendukung keputusan dalam pemilihan perumahan juga dilakukan oleh (Manao, Nadeak, \& Zebua, 2017) dengan metode SAW (Simple Additive Weighting) yang dapat menentukan nilai preferensi setiap alternatif, kemudian melakukan proses perangkingan alternatif terbaik dari sejumlah alternatif yang ada.

\section{RUMUSAN MASALAH}

Berdasarkan latar belakang judul usulan penelitian, maka rumusan masalah adalah bagaimana merancang dan membangun sebuah sistem pendukung keputusan tentang pemilihan perumahan dengan metode AHP dan GIS berbasis website.

\section{TUJUAN PENELITIAN}

Tujuan penelitian ini adalah membantu dan memudahkan bagi calon pembeli perumahan dalam mencari, memilih dan menentukan berdasarkan keinginan dan kemampuan calon pembeli tentang bentuk fisik perumahan, harga, fasilitas dan lokasi yang diinginkan.

\section{METODE PENELITIAN}

\section{A. Analisa Kebutuhan}

Tahapan pada penelitian ini dibagi menjadi dua metode yaitu pengumpulan data dan pengolahan data. 


\section{1) Metode Pengumpulan Data}

Metode pengumpulan data yang digunakan dalam penelitian ini adalah :

a. Wawancara

Metode pengumpulan data dengan cara mengadakan tanya jawab yang dilakukan secara langsung kepada para developer atau pemasar perumahan yang ada disekitaran Kota Banjarbaru dan calon pembeli.

b. Observasi

Pengumpulan data melalui pengamatan yang berkaitan dengan objek penelitian. Pengamatan dilakukan langsung secara observasi terhadap kriteria-kriteria fisik perumahan, harga dan lokasi yang sudah ada.

c. Studi Pustaka

Pengumpulan data dengan membaca serta mempelajari dokumen-dokumen, literatur, jurnal, dan buku-buku serta sumber lainnya misalkan internet yang berhubungan dengan Sistem Pendukung Keputusan, Metode AHP dan GIS.

\section{2) Metode Pengolahan Data}

Pengolahan data dalam Penelitian ini menggunakan metode AHP yang menggunakan kriteria-kriteria sebagai bobot yang mempengaruhi keputusan terhadap pemilihan perumahan berbasis website. Adapun tabelnya sebagai berikut:

Tabel 1Tabel Bobot Kriteria (AHP)

\begin{tabular}{|c|c|c|c|c|c|}
\hline Kriteria & 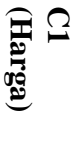 & 蛋 & ڤ & 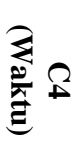 & 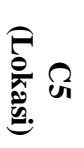 \\
\hline $\mathrm{C} 1$ & 1 & 2 & 3 & 4 & 5 \\
\hline $\mathrm{C} 2$ & 0.33 & 1 & 2 & 3 & 4 \\
\hline $\mathrm{C} 3$ & 0.25 & 0.5 & 1 & 2 & 3 \\
\hline $\mathrm{C} 4$ & 0.2 & 0.33 & 0.5 & 1 & 2 \\
\hline $\mathrm{C} 5$ & 0.166 & 0.25 & 0.33 & 0.5 & 1 \\
\hline
\end{tabular}

Studi kasus pada penelitian ini dengan pendekatan perluasan pemasaran perumahan menggunakan analisa kesempatan sasaran pemasaran, perancangan model sistem, fasilitas antarmuka calon pembeli, komunikasi pasar dan rancangan implementasi serta lokasi.

\section{B. Perancangan Penelitian}

Perancangan sistem basis data menggunakan metode pendekatan terstruktur. Metode ini lebih menekankan pada aliran data, yaitu Data Flow Diagram (DFD).

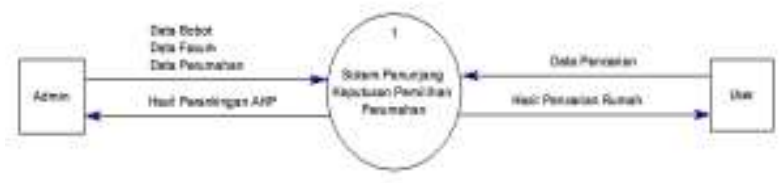

Gambar 1.1Diagram Konteks SPKPemilihan Perumahan Menggunakan AHP

\section{ANALISA HASIL DAN PEMBAHASAN}

A. Analisa Kebutuhan Input dan Output

Sistem pendukung keputusan pemilihan perumahan dengan metode AHP dan GIS diharapkan mampu menyelesaikan permasalahan - permasalahan yang ada pada calon pembeli selama ini keluhkan. Proses pencarian perumahan yang berbasis web, dan penentuan berdasarkan kriteria yang diingkan akan mengurangi kesalahan-kesalahan dalam menentukan rumah yang akan dibeli. Sisi fisik rumah pun dapat ditentukan langsung oleh sistem berdasarkan harga kemampuan calon pembeli hingga waktu yang dibutuhkan dalam kredit. Penentuan lokasi tak luput dalam penelitian ini, karena lokasi menentukan harga perumahan yang akan datang.

\section{B. Analisa objek penelitian}

Penelitian ini dilakukan padaPT. Lukah Banua Raya beralamat di Jl. Trikora Komplek Idaman Estate Kel. Guntung Paikat, Kec. Banjarbaru Selatan Kota Banjarbaruyang memiliki cabang di beberapa daerah dalam pemasaran perumahan.

\section{IMPLEMENTASI SISTEM}

a. Form Data Perumahan

Pada form ini digunakan untuk menginput data-data perumahan yang dipasarkan, mulai harga, tipe rumah, fasilitas, jenis sertifikat, serta titik lokasi nya. 


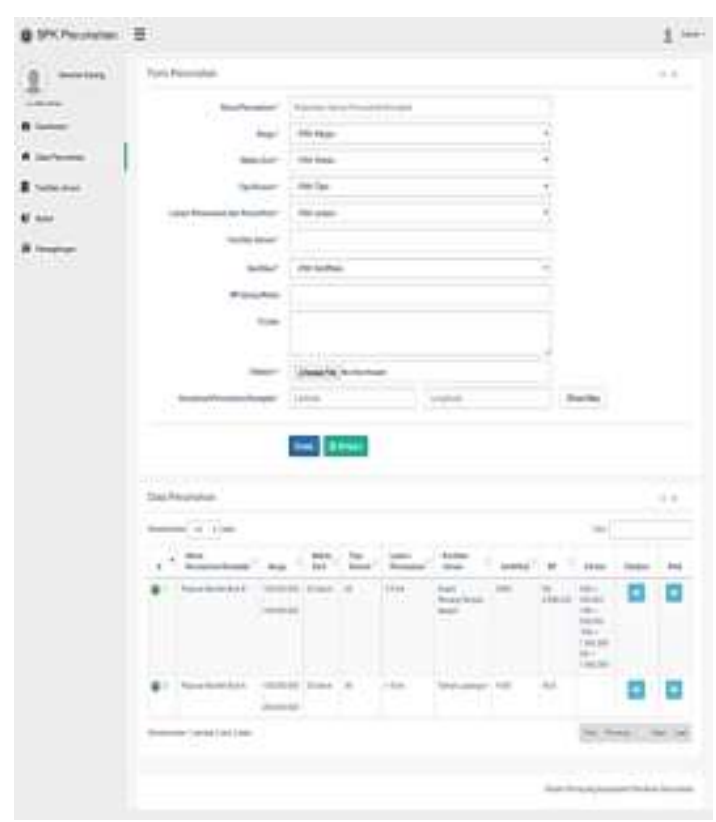

Gambar 2. Form Data Perumahan

b. Form Bobot Tiap Kriteria Pada Metode AHP

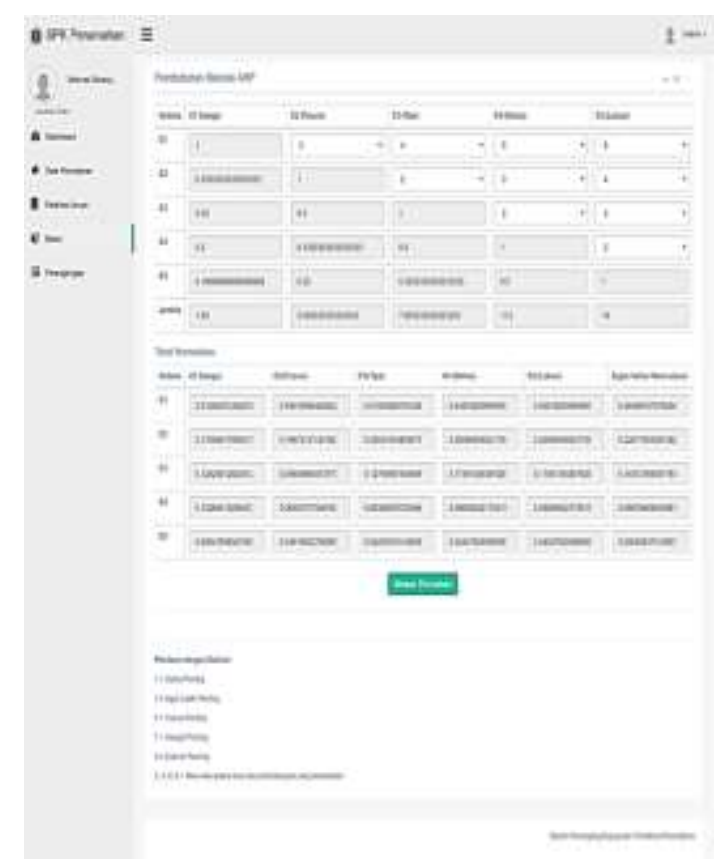

Gambar 3. Form Bobot Tiap Kriteria Pada Metode AHP

\section{PENUTUP}

\section{A. Kesimpulan}

Kesimpulan dari penelitian yang telah dilakukan adalah adanya fasilitas pencarian c. Form Hasil Perangkingan Menggunakan Metode AHP

Pada form ini digunakan untuk melihat hasil perangkingan perumahan mana yang paling cocok bagi calon pembeli.

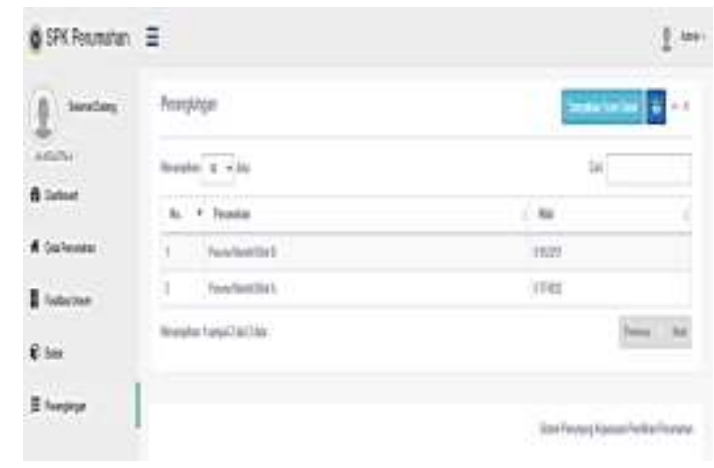

Gambar 4. Form Hasil Perangkingan Menggunakan Metode AHP

d. Form Tampilan Google Maps Letak Perumahan Dekat dengan Fasilitas Umum

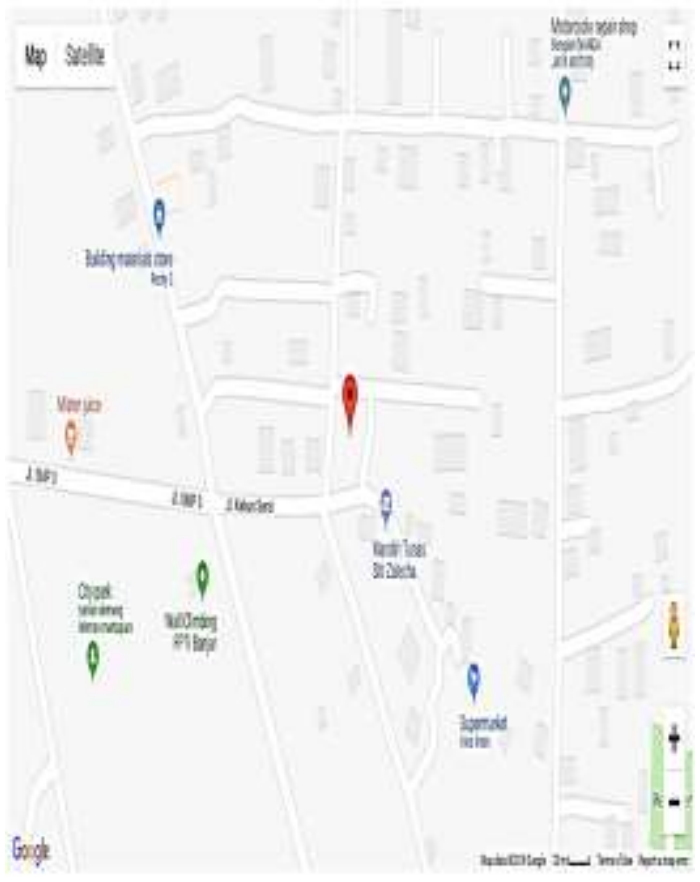

Gambar 5. Form Tampilan Google Maps Lokasi Perumahan yang Dekat Fasilitas Umum

perumahan berdasarkan fasilitas perumahan, harga, lokasi dan tipe perumahan dapat membantu calon pembeli perumahan dalam memilih perumahan yang sesuai dengan kebutuhan dengan metode perangkingan AHP 
didukung dengan pemanfaatan google Maps yang menunjukkan lokasi perumahan yang terdekat dengan fasilitas umum.

\section{B. Saran}

Kedepan agar penelitian ini dapat dikembangkan lagi dengan metode sistem pendukung keputusan lainnya agar lebih akurat, dan dapat dikembangkan juga dalam bentuk aplikasi android, mengingat banyaknya masyarakat pengguna aplikasi android yang free (tanpa berbayar) dan lebih memudahkan masyarakat.

\section{DAFTAR PUSTAKA}

Farizki, M., \& Anurogo, W. (2017). Pemetaan Kualitas Permukiman dengan Menggunakan Penginderaan Jauh dan SIG di kecamatan Batam Kota, Batam. Majalah Geografi Indonesia, 31(1), 39. http://doi.org/10.22146/mgi.24231

Kholdani, A. F. R., Muflih, \& Arminarahmah, N. (2017). Sistem pendukung keputusan penilaian kinerja dosen dengan metode ahp dan saw. JTIULM - Volume 2, Nomor 1, Juni 2017: 23 - 29 Berbasis, 23-29. Retrieved

from http://jtiulm.ti.ft.ulm.ac.id/index.php/JTIU LM/article/view/16

Manao, H., Nadeak, B., \& Zebua, T. (2017). Sistem Pendukung Keputusan Pemilihan Motor Dengan Metode Simple Additive Weighting (SAW). Media Informatika Budidarma, 1(2), 49-53. http://doi.org/10.33477/mp.v6i2.669

Panggabean, E. (2015). Sistem Pendukung Keputusan Penentuan Lokasi Perumahan Ideal Menggunakan Metode Fuzzy Simple Additive Weighting. Jurnal TIMES, IV(1), 12-17. Retrieved from http://ejournal.stmik-

time.ac.id/index.php/jurnalTIMES/article/ download/215/84
Puspitasari, D. I., \& Kholdani, A. F. R. (2017). Penerapan Sistem Pendukung Keputusan Dengan Analisis GAP Untuk Pemilihan Mahasiswa Berprestasi Tingkat Fakultas (Pada Fakultas Teknologi Informasi UNISKA). Technologia, 8(1), 1-9. Retrieved from http://ojs.uniskabjm.ac.id/index.php/JIT/article/view/716

Puspitasari, D. I., \& Kurniawan, M. Y. (2019). Location Based Services ( LBS ) for Searching Tire Repair Location in Banjarbaru City Based on Android. Jurnal Fisika Flux, Volume 1, . http://doi.org/10.20527/flux.v1i1.6150

Ramlan, F. M., Purwanto, E. H., Eosina, P., \& Susetyo, B. (2018). Sistem Informasi Pemasaran Rumah Berbasis Web GIS (Studi Kasus : Perumahan Bukit Sakinah). In Seminar Nasional Geomatika 2018: Penggunaan dan Pengembangan Produk Informasi Geospasial Mendukung Daya Saing Nasional (pp. 433-440). Retrieved from

https://www.researchgate.net/publication/ 331225372_SISTEM_INFORMASI_PE MASARAN_RUMAH_BERBASIS_WE B_GIS_Studi_Kasus_Perumahan_Bukit_ Sakinah

Riyanto, A., Bintro, K. B. Y., \& Pambudi, A. S. (2018). Sistem Pendukung Keputusan Penentuan Lokasi Strategis Pembangunan Perumahan Dengan Metode AHP. Jurnal INOVTEK Polbeng, 8(1), 78-86.

Zuo, Z., Jiangfeng, L., Yanzhong, L., \& Biao, C. (2009). Application of GIS and spatial decision support system for affordable housing. Proceedings of 2009 4th International Conference on Computer Science and Education, ICCSE 2009, (December), 1110-1115. http://doi.org/10.1109/ICCSE.2009.52285 54 